\title{
Criteria for Holobionts from Community Genetics
}

\author{
Elisabeth A. Lloyd ${ }^{1}\left[\right.$ ] Michael J. Wade ${ }^{2}$
}

Received: 17 December 2018 / Accepted: 20 March 2019 / Published online: 3 May 2019

(c) The Author(s) 2019

\begin{abstract}
We address the controversy in the literature concerning the definition of holobionts and the apparent constraints on their evolution using concepts from community population genetics. The genetics of holobionts, consisting of a host and diverse microbial symbionts, has been neglected in many discussions of the topic, and, where it has been discussed, a gene-centric, species-centric view, based in genomic conflict, has been predominant. Because coevolution takes place between traits or genes in two or more species and not, strictly speaking, between species, it may affect some traits but not others in either host or symbiont. Moreover, when interacting species pairs are embedded in a larger community, indirect ecological effects can alter the expected pairwise dynamics. Mode of symbiont transmission and the degree of host inbreeding both affect the extent of microbial mixing across host lineages and thereby the degree to which selection on one trait of either partner affects other aspects of a holobiont phenotype. We discuss several potential defining criteria for holobionts using community genetics and population genetics models, suggesting their application and limitations. Using community genetics models, we show how conflict between genomes can be self-limiting, while cooperation and mutualism tend to be self-accelerating. It is likely that this bias in the evolutionary dynamics of interaction between hosts and symbionts is an important feature of holobionts. This bias in the evolutionary dynamic could contribute to explaining the absence of cheaters from natural mutualisms, although cheaters are predicted by gene-centered conflict theory to cause the evolutionary instability of mutualisms. Additionally, it may help explain the more frequent origin of mutualisms from parasitic than from free-living systems, an evolutionary trajectory opposite to that predicted by genome conflict theory.
\end{abstract}

Keywords Holobiont · Hologenome · Interactors · Levels of selection · Microbiome · Mutualists · Replicators · Reproducers · Symbiont · Units of selection

\section{Introduction}

We take this to be the basic, initial definition of a holobiont:

Holobiont is a term used to describe an individual host and its microbial community, including viruses and cellular microorganisms (1-6) (Fig. 1). It is derived from the Greek word holos, which means whole or entire. Microbial symbionts can be constant or inconstant, can be vertically or horizontally transmitted, and

Elisabeth A. Lloyd

ealloyd@indiana.edu

1 History and Philosophy of Science and Medicine, and Biology Departments, Indiana University, Bloomington, IN, USA

2 Biology Department, Indiana University, Bloomington, IN, USA can act in a context-dependent manner as harmful, harmless, or helpful. (Theis et al. 2016, p. 1)

This definition encompasses a very broad range of ecological and evolutionary interactions between a host and its associated microbial community. It is agnostic in regard to how particular associations came about, that is, whether a symbiont came to be associated with a host via vertical transmission, horizontal transmission from another infected host, from host contact with the environment, or any combination of these pathways. It is agnostic in regard to the nature of the fitness consequences attending host-symbiont associations and the different levels of selection that might or might not be acting on one, two, or more associated organisms. The ubiquity of microbial communities associated with eukaryotic hosts raises the question of whether or not and to what degree natural selection has shaped these associations. Despite these relatively neutral aspects of the term holobiont, two opposing views have emerged in the literature, each 
importing different and additional assumptions which are not part of the definition above. In one view, the holobiont is a community that has evolved to be highly cooperative, with little conflict among its mutualistic members. Indeed, some have argued that a holobiont functions as though it were a single organism with cooperative parts shaped by natural selection acting at the level of the entire community. This is an adaptationist perspective of the holobiont as a biological entity. An opposing view expects, a priori, little cooperation and rampant conflict among the member species of the holobiont. And, absent mechanisms that restrict lower levels of selection, via an evolutionary transition après Szathmáry and Maynard Smith (1995), this view dismisses the likelihood that a higher level of selection might ever act on the holobiont as a unit or on any of the myriad of pairwise associations within it. This gene's-eye perspective sees "holobiont evolution" as a misnomer, since it is a loose assemblage of species with competing evolutionary interests bound not by cooperation but by a web of opportunity, manipulation, and coercion. Although this gene's-eye view tends also to be adaptationist, the suggestion of cooperation between individuals of different species is a bridge too far, for it is seen as a violation of Darwin's maxim, "If it could be proved that any part of the structure of any one species had been formed for the exclusive good of another species, it would annihilate my theory, for such could not have been produced through natural selection" (1866, p. 241).

The literature on holobionts encompasses few discussions of relevant genetic models, despite the pressing need to understand various aspects of the evolutionary dynamics of holobiont systems. Here, we introduce, explore, and contrast models that address some aspects of the conflicting views of the holobiont, emphasizing the conceptual constraints that derive from model assumptions. We show, using the philosophy of science approach called "The Logic of Research Questions" (Lloyd 2015; Lloyd and Oreskes 2018; Ketcham 2018), how conceptual commitments and model assumptions stemming from them affect the research questions asked, the data gathered, and the interpretation of holobionts. We argue that it is important to address the conflicting conceptual commitments that have shaped the controversy over the interpretation of the holobiont in order to understand whether or not and the degree to which coevolution has influenced holobiont associations.

Holobionts are likely to involve both coevolved and noncoevolved species groupings as well as beneficial and harmful interactions and multiple modes of transmission of the members of the microbial community (Douglas and Werren 2016; Queller and Strassmann 2016). We address here the dynamics of the potentially coevolved portions of holobionts, in which genes or genome segments from one species evolve against the background of the genes of another, and we highlight the conditions under which they may end up being coadapted, despite their belonging to distinct species. Although some have argued that adaptation to a biotic environment is no different from adaptation to an abiotic environment (e.g., Moran and Sloan 2015), we show why the process of interspecific coadaptation is often different from adaptation of a species to its abiotic environment. We also discuss the limitations on interspecific coadaptation and the conditions under which adaptation to a biotic environment is no different from adaptation to an abiotic environment. Moreover, we point out that some of the host-symbiont associations, sometimes used as examples of coadapted, integrated holobionts, might better be viewed as a one-way process of adaptation by one species to another with little or no reciprocal element. We offer a set of criteria against which candidate species groupings or entire holobionts can be compared, in order to determine their identity as "euholobionts," which we here define, by analogy with eusocial organisms, as genuine genetically integrated, coadapted communities of obligately mutualistic organisms. And, we offer the term "demibiont" to characterize one-way evolution, as opposed to reciprocal, coevolution between species. In ecology, commensalism refers to the situation wherein species one obtains benefits from species two without helping or harming species two, but it does not signify any degree of evolution by species one to its interaction with species two. Our definition of demibiont emphasizes the long-term adaptation by species one to species two and includes cases in which both species receive benefits from one another yet evolution affects (primarily) one of the two interacting species. For example, we consider the squid-vibrio interaction to be a demibiont because, while it is clear that the squid has evolved to depend upon the vibrio, it is not yet as clear that there has been a reciprocal adaptation on the part of the vibrio to the squid, since only a tiny fraction of the vibrio population is associated with a squid host. Euholobiont and demibiont are distinct from the adaptationally more neutral term "holobiont." Asymmetric fitness interactions and the evolutionary responses to them have played a central role in the coevolutionary dynamics of predator-prey systems and the conditions under which antagonistic coevolution may result in a predator-prey or host-pathogen arms race (Abrams 1986; Vermeij 1994; Brodie and Brodie 1999). Although the coevolutionary dynamics of commensalism and mutualism have received less attention (Leung and Poulin 2008; Bronstein 2015), we believe that an overt focus on host-pathogen interactions is, a priori, a biased model for holobiont evolutionary studies.

Before we proceed, we need to address a key definitional issue. There has been a debate in the literature over whether or not the holobiont is "a unit of selection," and, if so, is it the primary unit of selection? As Douglas and Werren (2016, p. 1) claim, "The hologenome approach focuses on one level of selection (the holobiont as a 'superorganism'), and as a 
result it is concerned with cooperative and integrative features of the 'hologenome' to the exclusion of other kinds of interactions." Although relevant as a skeptical response to the cooperative view of the holobiont as super-organism, our definition of holobiont (see above) makes no adaptive claim about units of selection. We argue that we need to ask the following questions in order to decide whether or not selection is acting at the level of the holobiont and, if it is, how strong that selection is with respect to other selective forces acting on the member species. Does a holobiont have the characteristics necessary to qualify as a unit of selection? Is the holobiont, as a community of organisms, an appropriate level to study evolution and evolutionary change (Lloyd 2018)? It is essential, in order to proceed in delineating holobionts, to review the various distinct meanings of the term "unit of selection," which does not connote a singular well-defined entity, but rather one of four possible selective and evolutionary roles (and their combinations). Have discussions of the holobiont carefully distinguished the roles of "interactor," "replicator" or "reproducer," or "manifestor of adaptation," and "beneficiary" ? ${ }^{1}$ We can advance understanding by identifying which role or roles we are referring to when discussing how evolutionary dynamics affect the characteristics of a holobiont.

A "unit of selection" may refer to a replicator or reproducer, an entity that is passed on, transmitted over generations, as more or less faithful copies of itself. This is the unit of selection in its reproductive role. But, there is also an ecological or interactive role for a unit of selection, which we, following Hull (1980), call an interactor: an entity that interacts, as a whole, with its environment in such a way that reproduction is differential relative to other interactants. There are many ways to represent the evolutionary interactor, most commonly as the level, locus, or target of selection. There can be many actors because selection can act at multiple levels simultaneously as in multilevel selection models (Wade 2016), or in holobiont selection processes (see Dupre 2012; Dupre and O'Malley 2013 and below; Lloyd 2018). Thus, both the host organism and its microbiota can undergo selection at several levels simultaneously, with a variety of potential outcomes, as we shall discuss below. Given the variety of outcomes possible in theory in two-species interaction models, we do not expect the majority of interactions among the members of a holobiont to be either antagonistic or cooperative. Moreover, given that adding an additional species to an ecological community can change the sign and magnitude of the fitness interactions between other species pairs (i.e., given indirect ecological effects; Wootton 1994),

\footnotetext{
${ }^{1}$ Lloyd (2001, 2017, 2018), Moran and Sloan (2015), Rosenberg and Zilber-Rosenberg (2018), Roughgarden et al. (2017), Griesemer (2000, 2016).
}

it is unlikely that current evolutionary genetic models, which predominately involve only two species, will be able to capture the richness of coevolutionary possibilities among the members of a holobiont.

As we note below, these distinctions affect the Logic of Research Questions or LRQs (Lloyd 2015; Lloyd and Oreskes 2018; Ketcham 2018) and constrain what is considered a responsive answer to a research question. For example, given the research question, "Who is cheating on whom?" all of the responsive answers have cheaters in them; so is either an absence of cheaters, or the presence of some degree of interspecific genetic integration, sufficient to refute the genome conflict interpretation of a holobiont? Or, assuming the research question (RQ) from the genome conflict view, "Is vertical transmission a host trait or a symbiont trait?" if vertical transmission is influenced by host genes, is that sufficient to establish its adaptive function as a mechanism evolved by the host for the adaptive purpose of limiting evolution of selfish symbionts? If, instead, vertical transmission is found to be a genetic adaptation of a symbiont and not the host, is that sufficient to refute the genomic conflict interpretation? Given the cheater/genomic conflict research questions, under which it is assumed that genomic conflict is virtually inescapable, is the observation of pathogenicity in an otherwise obligate mutualistic symbiont sufficient evidence to establish the absence of higherlevel selection and refute the cooperative interpretation of the holobiont? Clearly, a responsive answer to one or more of these RQs under one set of conceptual commitments may not be considered responsive or even relevant under a different set of commitments. Whether a holobiont is perceived in part or in total as a possibly ecologically or genetically integrated community or as a coercive, manipulative collection of genomes in conflict is affected by the research questions you start with. The possible and responsive answers that correspond to these RQs, and what data are collected and how those data are interpreted, are all constrained under the distinct LRQ.

We find that there have been two prominent confusions in the literature that lead to unfounded objections or critiques of the holobiont/hologenome concept. The first confusion involves the attribution of "evolutionary transition"-type, higher-order selection as a necessary precondition for holobiont evolution to have a cooperative, mutualistic dimension (Stencel and Wloch-Salamon 2018). In this view, a host and its loose association of microbes becomes a holobiont only if it first undergoes an evolutionary transition, because the holobiont must be the primary unit of selection in order to permit the evolution of an adaptive mutualism through the reciprocal coevolution of its component species. Without the primacy of holobiont-level selection, genomic conflict at lower levels of selection sustains disharmony among the evolutionary interests of the component species in a holobiont 
(Moran and Sloan 2015; Douglas and Werren 2016). Under this view, without the primacy of holobiont-level selection, which depends upon the choking-off of lower-level selection, cheater mutations, which benefit from but do not contribute to the holobiont, make mutualisms evolutionarily unstable. In contrast to this view, multilevel selection theory (Goodnight 2013; Wade 2016) admits the possibility of multiple, simultaneous (and possibly opposing) levels of selection at all stages of holobiont evolution, and is not dependent upon the prior occurrence of a major evolutionary transition. Multilevel selection does not identify a bottleneck, such as vertical transmission, as either a cause or a necessary condition for higher-level selection (Sober and Wilson 1998). Instead, multilevel selection can provide a pathway for the evolution of transmission modes and mating systems that enhance the efficacy of higher-level selection while diminishing that of lower-level selection. That is, we argue that multilevel selection precedes and attends, rather than follows, an evolutionary transition. And, as argued in Wade (2016), higher levels of selection may have access to pools of genetic variation unavailable to lower levels.

The second confusion has to do with not distinguishing the holobiont as an evolutionary interactor from the holobiont as an evolutionary reproducer, beneficiary, or manifestor of an adaptation (Lloyd 2017, 2018). Although each of these features affects the degree to which a holobiont can function as a unit of selection relative to other selection levels, most discussions emphasize only a single role. For example, Douglas and Werren (2016, p. 2) emphasize the role of holobiont primarily as a reproducer: "Partner fidelity is a prerequisite for the hologenome, because the host and its microbial partner(s) can only evolve as a unit if they co-occur across multiple host generations, with tight host genotype-to-microbe genotype matching." In contrast, Bosch and Miller (2016) emphasize the holobiont as interactor and manifestor of adaptations with minimal reference to reproducer or to evolutionary process. We therefore clarify these points of confusion below, and discuss community genetics models to further develop the relevant multilevel theory.

\section{Perceived Problems with the Holobiont as a Unit of Selection}

It is difficult to see how a holobiont can be considered an interactor with respect to unit of selection without interspecific epistasis. If evolution in response to the abiotic environment is no different than evolution in response to the biotic environment, then this aspect of interactor fitness is absent. Moreover, if the symbiont is a reliable component of the environment of its host, the distinction between horizontal and vertical transmission may well be moot. Moran and Sloan (2015, Box 1, p. 3) raise these concerns when they state: "Hosts may adapt to the reliable presence of symbionts in the same way that they adapt to abiotic components of the environment, and little or no selection on symbiont populations need be involved." In contrast, Bordenstein and Theis (2015, Box 1, p. 3) assert that, "Biomolecular associations between host and microbiota are more conceptually similar to an intergenomic, genotype $\mathrm{x}$ genotype interaction than a genotype $x$ environment interaction." In the next section, we discuss why Moran and Sloan's (2015) viewpoint might be accurate in or apropos to instances wherein a large fraction of a microbial species' population is free-living and only a small fraction are host-associated. These instances are not favorable to the evolution of vertical transmission or mutualistic interactions. However, we argue that in other cases the Bordenstein and Theis (2015) description of interactions is more accurate. And, these instances are more favorable to the evolution of both vertical transmission and mutualistic interactions. In general, it is an empirical question where on a continuum of transmission modes a host and one or more of its microbiota lie. We argue that an a priori commitment to a gene-centric, species-centric perspective and an assumption of genome conflict (Rice 2013) is an impediment to the investigation of this continuum.

An additional difficulty is the claim that there is an arms race based in genomic conflict underlying host and microbial coevolution. We address this concern in the "Is Genome Conflict Ubiquitous" section below. In addition, it is argued that in the arms race, antagonistic dynamics can be limited only when levels of vertical symbiont transmission from one generation of hosts to the next are extremely high. As per Douglas and Werren (2016, p. 5), when they ask about whether holobionts can evolve under a genic selectionist and cheater account: "The best predictor of whether an individual microbe and host evolve mutualistic "coadaptations' is whether specific host and microbial genotypes cooccur with high fidelity," where they equate high fidelity with either vertical transmission or with strong selection via "partner choice," i.e., nonrandom associations of host and microbe. It is argued that, because each species pursues its own evolutionary interests, an arms race is inevitable with any degree of horizontal transmission. As a result, the evolution of vertical transmission must precede the evolution of mutualistic cooperation between host and symbiont (see GodfreySmith 2009, 2012). The case is more difficult than the evolution of cooperation within species by kin selection because, "The advantage of indirect fitness from helping relatives is closed off to cooperation among different species" (Queller and Strassmann 2016, p. 860). This assumed relationship relating transmission and conflict under a cheater constraint can be found in Douglas and Werren (2016, p. 3; our emphasis): "For a host-microbiome association to be the unit of selection, the hologenome 
concept requires (near-) perfect concordance of selective interests both among the microbial partners and between the microbiota and host. As conflicts of interests among partners increase (e.g., due to weak partner fidelity), then the host microbiome is undermined as a single unit of selection." Similarly, Queller and Strassmann (2016) state that in order for selection at a higher level to functionally integrate a holobiont: "a higher-level entity can be considered organismal once it evolves extensive cooperation and very reduced conflict among its subunits." The a priori emphasis on conflict commits the answers to the RQs to those conforming to the restrictive assumption that the evolution of reduced conflict precedes higher-level selection acting on the holobiont.

Both confusions share the commitment, implicit or explicit, that levels of selection above the individual are ineffective, especially in so far as they involve multiple species. We address this concern in the "Levels and Units of Selection" section below. Moran and Sloan (2015, p. 6) claim that group selection is at best a weak evolutionary force and that, "population-level adaptations are unstable under most circumstances, due to susceptibility to invasion by selfish individuals." They then extend this viewpoint to holobionts, claiming that mutualisms are evolutionarily unstable, since cheaters of either species can subvert costly mutualistic adaptations. A similar argument led Williams (1966) to claim that, "good examples of mutualisms are relatively rare." And, Douglas and Werren (2016, p. 4), in pursuing the research question, "Can holobionts evolve as evolutionary mutualisms?" are explicit in stating that, as a result of genome conflict, lower-levels of selection predominate: "In summary, current understanding identifies the dominant processes shaping the evolutionary trajectory of vertically transmitted microorganisms to operate at levels of selection lower than the [holobiont] association." Here, as above, the gene's-eye focus commits the answers to the RQ to those conforming to the restrictive assumption that higher-level selection on holobionts is weak and ineffective. Some authors have gone further with this LRQ, and have claimed that vertical transmission is a host adaptation evolved for the purpose of stopping lower-level conflict among symbionts. For example, Burt and Trivers (2006, p. 150) state unequivocally: "The only explanation plausible to us is that ... uniparental mitochondrial inheritance is a system evolved by the nucleus [the host] to ensure mitochondrial quality."

We will address each of these objections in turn and introduce a discussion of units of selection more nuanced than that adopted by critics of the holobiont. Subsequently, we will introduce the LRQ and show, using empirical examples, how different conceptual commitments by researchers dictate what questions are asked and how data are gathered and interpreted.

\section{Evolution in Biotic and Abiotic Environments}

Only under certain circumstances is it true that, "Hosts may adapt ...to symbionts...in the same way that they adapt to abiotic components of the environment." Whenever the environment contains genes, as it does when the environment is biotic, the environment itself can evolve and become more or less common (Wolf et al. 1998), unlike abiotic environments whose frequency is independent of the organisms adapting to them. Adaptation to biotic environments allows for reciprocal dynamic effects such that an increase in allele frequency in one species can increase the rate of evolution of the other and vice versa. Abiotic environments, in contrast, do not evolve, under the typical population genetics geneenvironment approach, where the environment is a given. However, under the niche construction approach pioneered by Odling-Smee et al. (2003), the activities of the target organism can change features of the environment which, in turn, affect the rate of future evolution of that species as well as possibly the rates of a myriad of other species. This latter possibility from niche construction theory has not been discussed by those criticizing the holobiont concept, so we will not introduce it here although it has significant merit and relevance in this context.

To illustrate the difference between adaptation to biotic environments relative to abiotic environments, we let $H$ represent an allele in the host species which is advantageous in the selective, abiotic environment $1\left(\mathrm{E}_{1}\right)$, increasing host fitness by $s$, but neutral in abiotic environment $2\left(\mathrm{E}_{2}\right)$. We let $p_{H}$ be the frequency of the $H$ allele and $f_{l}$ the frequency of $\mathrm{E}_{1}$ and $\left(1-f_{1}\right)$, the frequency of $\mathrm{E}_{2}$.

We imagine that the host is randomly distributed over the selective and neutral abiotic environments so we have

$\Delta \mathrm{p}_{\mathrm{H}}=\left(\mathrm{sf}_{1}\right)\left(\mathrm{p}_{\mathrm{H}}\right)\left(1-\mathrm{p}_{\mathrm{H}}\right) / \mathrm{W}_{\text {Host }}$

where $\mathrm{W}_{\text {Host }}$, equal to $1+s f_{l} p_{H}$, is the mean fitness of the host. Note, in Eq. 1, that the strength of selection, $s f_{1}$, increases with $f_{1}$, the frequency of the selective abiotic environment. When $\mathrm{E}_{1}$ is common, the rate of host adaptation to the selective environment is faster and, conversely, when $\mathrm{E}_{1}$ is rare, $f_{1}$ is small, and adaptation is very slow. In fact, it is almost impossible for a species to adapt to an extremely rare environment where $f_{1} \sim 0$ because most copies of most genes experience a different, more common environment where they are not screened by natural selection for "fit" to the features of the rare environment.

Now consider a biotic environment wherein a symbiont is always host associated and hosts always harbor symbionts. (We relax this assumption later.) We let $H$ represent an allele in the host and $m$ represent an allele in the microbial symbiont in the following. Imagine that the $H$ allele in the host changes its bearer's fitness by $s$, but only in the presence of a particular microbial genetic background, $m$, where $p_{m}$ is 
the frequency of this background. Imagine also that the $m$ allele in the microbe changes its bearer's fitness by $t$, but only in the presence of a particular host genetic background, $H$, where $p_{H}$ is the frequency of this background. Moreover, allow hosts and microbes to assemble at random into H-M pairs. Now we have

$\Delta \mathrm{p}_{\mathrm{H}}=\left(\mathrm{sp}_{\mathrm{m}}\right)\left(\mathrm{p}_{\mathrm{H}}\right)\left(1-\mathrm{p}_{\mathrm{H}}\right) / \mathrm{W}_{\text {Host }}$

and

$\Delta \mathrm{p}_{\mathrm{m}}=\left(\mathrm{tp}_{\mathrm{H}}\right)\left(\mathrm{p}_{\mathrm{m}}\right)\left(1-\mathrm{p}_{\mathrm{m}}\right) / \mathrm{W}_{\text {Microbe }}$

where $\mathrm{W}_{\text {Host }}$, equal to $1+s p_{m} p_{H}$, is the mean fitness of the host and where $\mathrm{W}_{\text {Microbe }}$, equal to $1+t p_{m} p_{H}$, is the mean fitness of the microbe.

Clearly, $\left(s p_{m}\right)$ in Eq. 2a has replaced $\left(s f_{1}\right)$ in Eq. 1 and the strength of selection on the host population increases as $p_{m}$ increases, just as the strength of selection on the microbial population $\left(t p_{H}\right)$ increases as $p_{H}$ increases. When the fitness effects are positive $(s, t>0)$, then the selective biotic environment of the host becomes more common each generation because $p_{m}$ increases to $\left(p_{m}+\Delta \mathrm{p}_{\mathrm{m}}\right)$, and the biotic environment of the symbiont becomes more common each generation because $p_{H}$ increases to $\left(p_{H}+\Delta \mathrm{p}_{\mathrm{H}}\right)$. If either were, instead, an abiotic selective environment, say $\mathrm{E}_{1}$ above, with the same fitness effect, $s$, the strength of selection represented by $\left(s f_{l}\right)$ in Eq. 1 would not change over generations, because the frequency of the selective abiotic environment, $f_{l}$, does not change (i.e., $\Delta f_{l}=0$ ) in response to a change in the biotic environment. Thus, in general, adaptation to a biotic environment can be significantly different from adaptation to an abiotic environment. Adaptation to a biotic environment is more like frequency-dependent selection where the selection coefficient changes with the frequency of the allele conferring adaptation to it, but in this case, the frequency-dependence lies with an allele in an associated species ([sp $\left.p_{m}\right]$ for the host and $\left[t p_{H}\right]$ for the symbiont) and not in the species directly experiencing selection.

Moreover, if $\mathrm{p}_{\mathrm{m}}$ and $\mathrm{p}_{\mathrm{H}}$ are evolving, their change in magnitude must be accounted for along with the respective $\Delta \mathrm{p}_{\mathrm{H}}$ and $\Delta \mathrm{p}_{\mathrm{m}}$ equations. This is unlike the abiotic case, where $\Delta f_{l}$ is zero by assumption and change in it need not be accounted for. Thus, the statement by Moran and Sloan (2015, Box 1, p. 3) that, "Hosts may adapt to the reliable presence of symbionts in the same way that they adapt to abiotic components of the environment, and little or no selection on symbiont populations need be involved," is false, in general. It is only true in the uninteresting cases where (1) both $\Delta \mathrm{p}_{\mathrm{H}}$ and $\Delta \mathrm{p}_{\mathrm{m}}$ are so close to zero that there is little or no coevolution; or, (2) $t=0$ and $s>0$, which returns us to the abiotic case.

For the biotic case to be just like the abiotic case, clearly, the rate of host evolution, $\Delta \mathrm{p}_{\mathrm{H}}$, would have to be independent of $p_{m}$ and hence independent of symbiont evolution. Similarly, the rate of symbiont evolution, $\Delta \mathrm{p}_{\mathrm{m}}$, would have to be independent of host evolution. This could occur if we imagined that there was another, much more common, third environment. Imagine that the most common symbiont environment is a nonhost associated, free-living state, $\mathrm{E}_{3}$, where $\mathrm{f}_{3} \sim 1$ and similarly, the most common host microbial environment is to be noninfected. In that case, even if Eqs. $2 \mathrm{a}, 2 \mathrm{~b}$ held, the symbiont population would not experience strong coevolutionary selection with the host because the very large majority of symbionts would experience a different, nonhost associated environment. Likewise, the host population would not coevolve with the symbiont because the very large majority of hosts would not experience infection by the symbiont. Alternatively, the free-living state, $\mathrm{E}_{3}$, with $\mathrm{f}_{3} \sim 1$, could be paired with the state in which all hosts were infected. This would allow the host to adapt to the symbiont, but not the reciprocal. As mentioned above, we refer to associations characterized by the evolution of one but not the other partner as demibionts, and we will illustrate this type of evolution in a later section using the vibrio-squid example.

We acknowledge that, although our model has the most direct connection to one-locus, classic G x E models, there are other, nonlinear ways to set up models of two-species gene frequency change. For example, in a predator-prey system, we might imagine that the optimum of one species is dependent upon a trait or allele frequency in the other. If so, we might express selection in the host as a function like ( $\left.\mathrm{s}\left[\mathrm{p}_{\text {host }}-\mathrm{p}_{\text {symbiont }}\right]\right)$ and reciprocally in the symbiont $\left(\mathrm{t}\left[\mathrm{p}_{\text {symbiont }}-\mathrm{p}_{\text {host }}\right]\right)$. This type of selective interaction does not lead to runaway evolutionary dynamics. In general, there is an asymmetry in the coevolutionary process between predator and prey such that there is a "predominance of evolutionary responses of prey to predators over those of predators to prey [which] is in general accord with equilibrium theory" (Abrams 2000, p. 79).

\section{Is Genome Conflict Ubiquitous?}

The second argument against the holobiont as a unit of selection goes further, arguing that it is likely that, if host and symbiont are coevolving, it is because they are in an evolutionary arms race of genomic conflict (e.g., Rice 2013). The Wikipedia definition of an evolutionary arms race (accessed April 5, 2019: https://en.wikipedia.org/wiki/Evolutionary_ arms_race; our emphasis) is this: "an evolutionary arms race is a struggle between competing sets of coevolving genes, traits, or species that develop adaptations and counter-adaptations against each other, resembling an arms race. These are often described as examples of positive feedback" (e.g., Crespi 2004; but see Abrams 1986). Let's consider this claim from the viewpoint of our model introduced above. 
Clearly, "positive feedback" does not necessarily result in a runaway process of coevolution; but we are interested in those cases in which it does. Similarly, "negative feedback" does not necessarily result in a decelerating process although in single locus models like ours and like those of the "gene's-eye view" of interspecific conflict it tends to. In the case of the postulated gene-level conflict between host and symbiont genes, for a trait in one species, like virulence in the symbiont or resistance in the host, either $s$ or $t$ is negative, so that one of the terms, $\Delta \mathrm{p}_{\mathrm{H}}$ or $\Delta \mathrm{p}_{\mathrm{m}}$, is negative while the other is positive, but diminishing. To see this, we assume that $s<0<t$, for the selective effects perpetrated by one species on the other. As a result, the term $\left(s p_{m}\right)$ in Eq. $2 \mathrm{a}$, the host evolutionary equation, diminishes the frequency of $p_{H}$. And, although $\left(t p_{H}\right)$ in Eq. $2 \mathrm{~b}$, the force of selection in the microbe evolutionary equation, is positive, it becomes smaller over time because $p_{H}$ declines from one generation to the next. ${ }^{2}$ Differently put, the harmful symbiont reduces the frequency of the host genotypic environment on which it thrives, making it more difficult for its own offspring to find a suitable host environment and be rewarded by selection. When the reciprocal is true, $t<0<s$, the host reduces the frequency of the symbiont genotype that it resists; the rarer the virulent symbiont, the less frequently will host offspring encounter the environment that justifies a costly defense. As a result, with genomic conflict, both $\Delta \mathrm{p}_{\mathrm{H}}$ and $\Delta \mathrm{p}_{\mathrm{m}}$ tend to diminish. This is not an arms race, because there is no positive feedback between the species, but rather a movement of cross-specific gene frequency disengagement in both species. The evolutionary dynamic does not meet the arms race criterion of "positive feedback," and without such feedback, it is not clear that both species will adapt to one another with greater and greater investment. In fact, under the model above, the evolutionary feedback between the two species diminishes over time.

Very significantly, in the mutualistic case $(\mathrm{s}, \mathrm{t}>0)$, there is reciprocal positive feedback because the terms $\left(s p_{m}\right)$ in Eq. 2a, the host evolutionary equation, and $\left(t p_{H}\right)$ in Eq. 2b, the microbe evolutionary equation, become larger over time because $\mathrm{p}_{\mathrm{m}}$ and $\mathrm{p}_{\mathrm{H}}$, respectively, increase from one generation to the next. Under the Logic of Research Questions of genomic conflict, the two equations disengage, and mutualisms are thereby very fragile; but under the LRQ of mutualistic coevolution, we get not only robust mutualistic coevolution, but under some conditions, an actual runaway

\footnotetext{
2 This is the argument for the evolution and maintenance of sex in host species by pathogens: the more common the host genotype, the stronger the selection against it by the pathogen (tph). For that reason, the host is under constant selection to produce rare offspring genotypes to escape the pathogen. Sexual reproduction by the host is an adaptation for the production of these rare escape variants (Lively and Morran 2014).
}

process of mutualism (e.g., Drown and Wade 2014). In other words, the contrasting LRQs make fundamentally opposing predictions about the stability of mutualisms in nature. It must be therefore also significant that there has never been discovered a macroorganism with no microbial partners.

Nonrandom Associations between Species: Now consider that instead of randomly assembling pairs of genotypes across species, we imagine that certain H-M combinations have a greater-than-random frequency either after selection as a result of synergistic epistatic fitness favoring some H-M combinations over all others or before selection owing to partner choice, to vertical transmission, or to host-symbiont population genetic structure. Note first that our approach is founded on consideration of the full spectrum of interspecific epistatic effects. That is, a host gene can have a positive, neutral, or negative direct effect on the host and a positive, neutral, or negative fitness effect on the symbiont, and vice versa. As we have seen above, $[+,+]$ interactions between species, which can give rise to mutualisms, are particularly interesting in terms of the resulting evolutionary dynamics. In contrast, the genomic conflict perspective is focused almost exclusively on genes with $[+,-]$ or $[-,+]$ epistatic interspecific interactions. That is, the conceptual bias favored by the genome conflict LRQ is the primary reason for the exclusive focus of the RQ on genes with a positive direct effect on host fitness but a negative indirect effect on the fitness of an associated symbiont, or vice versa. This is founded on the axiom that the evolutionary interests of two species are rarely if ever aligned without very high fidelity of co-transmission.

One could note that mutations with a direct positive fitness effect are much rarer than those with a direct negative, deleterious fitness effect, and, similarly, it might be (but has not been) argued that mutations of one epistatic type of interspecific interaction will be more common than mutations with the $[+,+]$ direct and indirect fitness effects that underlie mutualisms. Just as the sieve of natural selection brings adaptations to the fore, despite the relative rarity of mutations with direct positive effects on fitness, we suggest that the positive feedback that attends mutations with $[+,+]$ interspecific epistatic fitness effects may play an analogous role in the evolutionary dynamics of mutualisms. However, there are almost no studies of the distribution of indirect fitness effects and those that exist are within species (Bijma 2014). However, the few studies that have been done support the conclusion that, "The increasing research effort devoted to IGEs [indirect genetic effects] suggests that they are a widespread phenomenon, probably particularly in natural populations and plants" (Bijma 2014, p. 61).

Consider the case of $[+,+]$ interactions. Here, we have selection on initially random host-microbe combinations creating an interspecies linkage disequilibrium, $\mathrm{ILD}=G_{H, m}-p_{H} p_{m}>0$. This changes Eqs. $2 \mathrm{a}, \mathrm{b}$ above to 
$\Delta \mathrm{p}_{\mathrm{H}}=\left(\mathrm{sG}_{\mathrm{Hm}}\right)\left(1-\mathrm{p}_{\mathrm{H}}\right) / \mathrm{W}_{\mathrm{H}}$ and

$\Delta \mathrm{p}_{\mathrm{m}}=\left(\mathrm{tG}_{\mathrm{Hm}}\right)\left(1-\mathrm{p}_{\mathrm{m}}\right) / \mathrm{W}_{\mathrm{M}}$.

The changes in $\Delta \mathrm{p}_{\mathrm{H}}$ and $\Delta \mathrm{p}_{\mathrm{m}}$ are again positive but are now larger because in both equations, ILD $=G_{H, m}-p_{H} p_{m}>0$. To see this better, we can rewrite $G_{H, m}$ as the sum, $p_{H} p_{m}+$ ILD $>0$. Like epistasis for fitness in two-locus nuclear gene models, the equations, $\Delta \mathrm{p}_{\mathrm{H}}$ and $\Delta \mathrm{p}_{\mathrm{m}}$, alone are theoretically insufficient to characterize the coevolutionary process; an expression for $\Delta \mathrm{G}_{\mathrm{Hm}}$ is now essential for modeling. However, with random horizontal transmission among host genotypes, $G_{H, m}$ becomes equal to $\left(p_{H} p_{m}\right)$ at the start of each generation because the random mixing of twospecies genotypes reduces ILD to zero. (Horizontal transmission with random mixing is not semiconservative like recombination with respect to nuclear gene combinations and within-genome LD.) Some vertical transmission, $v$, is necessary to preserve the ILD established by selection on host-symbiont gene combinations, so that it is vILD at the beginning of a generation instead of 0 .

Where does vertical transmission come from? How might vertical transmission evolve? Is it really the case that the "only explanation plausible" is that vertical transmission evolves as a host adaptation for the purpose of shutting off lower-level, within-host symbiont selection? Fogarty and Wade (in prep.) show, using formal genetic models of niche construction, that vertical transmission can evolve as a symbiont adaptation. Moreover, they show that positive niche construction precedes the evolution of vertical transmission because it is the niche construction that allows the evolution of vertical transmission in the first place. These findings are contradictory to the predictions from conflict theory, which imagines that vertical transmission is a prerequisite, necessary to allow the evolution of beneficial symbionts and restrict the evolution of selfish or pathogenic ones. Second, theoretical models have shown that, whenever there are genes with $[+,+]$ epistatic fitness effects and genetic variation affecting transmission mode, mutations that increase vertical transmission in either the host or the symbiont genomes hitchhike to higher frequency on the spread of the synergistic epistatic genes (Drown et al. 2013). In addition, fluctuating environments also allow for the evolution of vertical transmission (Ram et al. 2018). Drown et al. (2013) asked the RQ: "What evolutionary forces are necessary to evolve from an ancestral state of horizontal transmission to a derived state of vertical transmission?" The processes of selection that they analyzed resulted in robust, runaway processes of mutualism, wherein many states in the system all converge on mutualistic ones, the exact opposite of the fragile mutualistic states resulting from the cheater/ genomic conflict models.
Turning to the data, we find the following. First, molecular phylogenetic studies show that mutualistic bacteria are derived more frequently from parasitic or disease-causing ancestors than they are from free-living species (Sachs et al. 2014). These parasitic ancestors may have evolved some degree of vertical transmission as an adaptation to finding new hosts. This is a plausible explanation for the evolution of vertical transmission as a symbiont adaptation as opposed to a host adaptation. Second, contrary to the prediction of genome conflict theory, empirical data indicate that, once bacterial mutualisms are established, they rarely return to parasitic or free-living states (Sachs et al. 2011; Weiblen and Treiber 2015). Similarly, among approximately 13,500 mycobiont mutualistic lichen symbionts, taxonomic analyses indicate only a single transition to an endophyte but many transitions, nearly in equal frequency, from endophyte to pathogen or vice versa (Arnold et al. 2009). These observations contradict the predictions from conflict theory that mutualisms are evolutionarily unstable and that symbionts will devolve into parasites or disease-causing pathogens (see above).

Moreover, if we isolate an interspecific, epistatic component of fitness, $e$, we could rewrite $s$ as $(s+e)$ and $t$ as $(t+e)$. Here, the $e$ component of fitness does not "belong" to either the host or the microbe, but rather to the particular trans-specific genotype combination, H-M. We might reasonably call this H-M combination a "pre-holobiont" or a "holobiont genotype." Relative to features of holobionts as units of selection (see the next section), a component of interspecific epistasis $(e \neq 0)$ establishes a holobiont as a unit of selection in terms of an interactor and some degree of vertical transmission $(v>0)$ establishes a holobiont as a unit of selection in terms of a reproducer. Where Bordenstein and Theis (2015, Box 1, p. 3) emphasize that, "host-microbe associations can forge disequilibria via parental transfer or stable environmental transmission," instead, we are here emphasizing the classical evolutionary genetic approach wherein selection acting on random combinations with interspecific epistasis creates ILD and vertical transmission enhances the heritability of those favorable combinations. ILD can also be created by some, but not all, types of "partner choice," a form of host-symbiont selection analogous to mate selection. However, without inbreeding, population genetic structure, or vertical inheritance, partner choice in one generation is not transmitted across generations. It is important to emphasize that we are not claiming that there is "only" interspecific epistasis for fitness between a host and its microbial partner(s); we are saying that without epistasis there is no identifiable "fitness" component unique to the holobiont, supra-individual level. 


\section{Levels and Units of Selection: Evolutionary Transitions and Suppressing Cheaters}

\section{The Suggestion that the Holobiont Must be the Primary} Unit of Selection: Moran and Sloan (2015) correctly characterize the holobiont/hologenome project, as involving "participating [genetic] lineages within a holobiont that affect each other's evolution," but go on to suggest that it is a misconception that "the holobiont is a primary unit of selection" (2015, Box 1, Misconceptions related to the hologenome concept). Their aim (p. 2) is "to clarify what kinds of evidence are needed for each of these claims and to argue that neither should be assumed without evidence." It is fair to say that no one is making suggestions in the absence of supporting evidence, but let us see what they suggest is wrong with the evidence available to us, and consider the array of concerns commonly voiced against the holobiont as a unit of selection.

Before we address the process as it has been applied to the holobiont, we must first understand that coevolution does not affect every gene in both species. Instead, it need only affect one gene in each species and may also include interspecific epistasis. That is, coevolution does not take place between whole species or between whole genomes; it takes place between traits or genes between species (Keister et al. 1984a, b; Wade 2007; Weiblen and Treiber 2015). Without this distinction, we cannot understand the dynamics of coevolution of the members of a holobiont community.

Moran and Sloan state that "coevolution and codiversification are likely common for hosts and associated microorganisms," but argue that,

the proposals that the hologenome is the primary unit of selection and that microbes can be equated to genes within a larger genome are far more sweeping claims. They imply that selection on constituent genomes acts primarily to increase fitness at the level of the holobiont, that is, that conflicts between the evolutionary interests of host and symbionts are suppressed due to selection at the higher level. Even demonstrating coevolution does not necessarily imply that hologenomes are a significant unit of selection. (2016, p. 5; our emphasis)

We agree that equating a microbe to a host gene makes little sense from the viewpoint that coevolution takes place between genes and not between species. Differently put, it is unlikely, except perhaps in the most extreme cases of genome reduction, that every gene in the genome of an obligately mutualistic microbe could be considered "a host gene." Whether considered host genes or not, genes with different transmission modes, specifically biparental nuclear and uniparental maternal inheritance, will continue to experience the effects of many evolutionary forces, like drift, mutation, and selection, differently. Only in the case of intergenomic gene transfer (Adams et al. 1999; Brandvain et al. 2007) would we expect a microbial gene to experience evolutionary forces in a manner similar to other genes in the host nuclear genome.

Note as well that, in the above quote, Moran and Sloan are not only attributing the Maynard Smith/Szathmary evolutionary-transitions type of group selection to holobiont selection models (see "Is Genome Conflict Ubiquitous?" section above), but also they claim that holobionts can be the primary unit of selection, only when lower levels are suppressed. The Maynard Smith/Szathmary evolutionary-transitions type of group selection is explicitly endorsed by Douglas and Werren (2016, p. 5): "The groundbreaking book The Major Transitions in Biology makes a convincing argument that most of the major biological transitions have involved the evolution of mechanisms that reduce conflict and competition at one biological level, facilitating the evolution of a higher biological level.” Burt and Trivers (2006) argue, more specifically, that vertical transmission is an adaptation by the host for the purpose of suppressing lower-level selection. Moreover, once vertical transmission is in place, Moran and Sloan argue that the host and symbiont should co-diversify and co-speciate giving rise to phylogenetically congruent trees. These claims conflict with the view of holobionts and the evolutionary dynamic processes that we advance here. Just as it is unrealistic to consider a microbe to be a host gene, it is difficult to project patterns of co-speciation into the deep evolutionary past when the microevolutionary processes influencing host-symbiont coevolution remain a point of extreme contention.

We would agree in part with Moran and Sloan (2015, p. 6) that, "the evolution of microbial lineages must also be contributing to increased holobiont fitness" if the meaning applies to the interspecific epistatic component of selection, $e>0$, as we argued above. However, unlike Moran and Sloan (2015) we do not require that this make the hologenome the primary unit of selection to the exclusion of other levels acting on other genes or traits of either the host or the microbe in question. That is, we do not hold the position that holobionts are the only or even the primary unit of selection; rather, our argument is that, whenever there is interspecific epistasis for fitness, the evolutionary dynamic of the holobiont involves a higher level of organization at which selective processes operate in addition to selective processes at lower levels. Our picture is one of a dynamic evolutionary process consisting of multiple levels of operation and selection simultaneously (see Wade 2007, 2016; Dupré 2013; Roughgarden et al. 2017; Lloyd 2018).

The Claim of the Ubiquity of Cheaters and Superior Efficacy of Lower Levels of Selection: We would like to 
emphasize how much our epistatic models are in conflict with the classic gene's-eye "cheater" view. In the typical gene's-eye case, mutualisms are evolutionarily unstable because cheater mutations in either partner can reap the fitness benefits of mutualism without incurring the fitness costs of contributing to the common good (Akcay 2015, Chap. 4 in Mutualisms). Indeed, in discussing group selection, Williams (1966, p. 247) claimed that, for this reason, "good examples of mutualisms are relatively rare." (This is similar to the argument by May (1971) that large communities structured by interspecific competition are ecologically unstable.) However, under the models proposed here (and implicit in some other holobiont approaches; e.g., Zilber-Rosenberg and Rosenberg 2008; Bordenstein and Theis 2015; Theis et al. 2016; Roughgarden et al. 2017; Lloyd 2018; Rosenberg and Zilber-Rosenberg 2018), it is the mutualists that will experience runaway selection, while it is the cheaters that are self-limited by selection.

Such cheater mutations are the basis of the claim by Moran and Sloan (2015, p. 6) that the holobiont/ hologenome approach has many parallels with group selection. They state: "Early and oversimplified views of group selection... failed to recognize that population-level adaptations are unstable under most circumstances, due to susceptibility to invasion by selfish individuals." They are right, in that holobiont evolutionary dynamics involve genuinely hierarchical, multilevel selection models. They draw incorrect conclusions from this, however, about the relative efficacy and stability of the units of selection.

Let us consider this matter more closely, as it has been addressed previously in the literature on the evolution of cooperation in multilevel selection models. First, Wade and Breden $(1980,1981)$ showed that cheaters do not invade kin selection models, which are forms of group selection models (Wade 1980; Bijma and Wade 2008). They showed that the necessary and sufficient conditions for a cheater allele to invade and spread through a population of altruists violated the necessary and sufficient conditions for an altruistic allele to spread in the first place. That is, the same population structure that permits the evolution of altruism precludes invasion by selfish alleles. The belief that a selfish allele can always increase within a group and become prevalent in a species that was previously altruistic is founded on the incorrect and implicit bias that lower-level, within-group selection is always stronger than higher-level, among-group selection. We believe that a similar emphasis on selection at the level of single gene differences among individuals and indifference to the potential effects of higher-level community selection is the basis for the counterfactual claim that mutualisms are evolutionarily unstable.

Second, Van Dyken and Wade (2012) showed that multilevel selection models achieve a "kin selection-mutation balance," wherein so-called "cheater" alleles exist, but $d o$ not spread. Instead, they remain at low frequency owing to opposing kin selection, similar to deleterious mutations affecting "ordinary" nonsocial traits. Van Dyken and Wade (2012) also proposed an empirical test of which hypothesis, the "cheaters win" or the "kin selection-mutation balance," was correct. We believe that their empirical test can be extended to mutualisms. Their test is based on the allele or site frequency spectrum (Bustamante et al. 2001), the distribution of the frequencies of a given locus or loci in a population or sample. When cheater mutations enjoy a selective advantage, the frequency spectrum should differ from the spectrum under the "kin selection-mutation balance" hypothesis. Under the "cheaters win" hypothesis, the site frequency spectrum should have a "fat tail," because those mutations that destroy costly contributions to a mutualism but enjoy the fitness benefits of the mutualism will be more common than expected at mutation-selection balance. Moreover, larger mutations, i.e., those that totally destroy costly function versus those that simply impair or diminish function, should be relatively more common because they enjoy a higher fitness at the lower level, owing to best minimizing the costs of participation. Our genetic theory is empirically supported, prima facie, by a recent article by Jones et al. (2015) in which no cheaters were documented in nature by a group of strong advocates of the cheaterswin hypothesis and the gene's-eye point of view. In their own words (Jones et al. 2015, p. 1270): "Cheating is a focal concept in the study of mutualism, with the majority of researchers considering cheating to be both prevalent and highly damaging." They proposed an appropriately strict, fitness-based definition of cheating, and then tested the traditional, "best-studied" exemplars of mutualisms in nature for fulfillment of these requirements for cheaters. Jones et al. (2015, p. 1270) conclude (our emphasis): "We find... there is currently very little support from fitness data that any of these meet our criteria to be considered cheaters." They suggest future directions for research on conflict in mutualisms, "including novel research avenues opened by a relative-fitness-based definition of cheating," by which they mean exploring whether cheating is occurring by other means besides giving less reward to the partner (Jones et al. 2015, p. 1281). Phylogenetic studies of mutualisms in nature provide further evidence against the claim that holobionts are vulnerable to cheaters. As stated in a review by Weiblen and Treiber (2015, p. 45):

Molecular phylogeny suggests that mutualistic bacteria have evolved more often from parasitic than from free-living ancestors (Sachs et al. 2014)....Contrary to theoretical models predicting that mutualists could be vulnerable to extinction and reversal to parasitism... empirical data suggest that once bacterial lineages 
evolve to be mutualists, they rarely return to parasitic or free-living states. (Sachs et al. 2011)

One might argue further that other adaptations for suppressing conflict, like policing, can keep cheaters rare despite their repeated introduction into populations by mutation and their individual fitness advantage. However, Brandvain and Wade (2007) modeled the evolution of policing and found that it required among-group selection. That is, an allele for policing introduced at low frequency spreads only when there is selection between groups that vary in fitness owing to variation in the frequency of cheaters and variation in the frequency of the policing allele. This dependence on a higher level of selection to evolve a policing mechanism is incompatible with the theory that predicts cheaters in the first place.

We see related arguments in the section on "levels of selection," where Douglas and Werren (2016, p. 3) acknowledge that selection can act at "multiple levels of biological organization." However, they impose stringent conditions on higher levels of selection, stating that, "[s]election at higher organizational levels is predicted to be significant where there is a strong overlap of selective interest among the constituent entities, e.g., genes on a chromosome, cells in the body of a multicellular organism, honey bees in a hive." Note that their analysis implicitly adopts the approach that the emergence of new, more complex levels of biological organization only occur once lower levels of selection are halted or impaired. The first step in this emergence is the successful transition from independent replicators to higherlevel units. This requires that "evolution at the lower level must be somehow constrained by the higher level" and that there be synergistic fitness interactions among the lowerlevel units in the collective (for example, Szathmary 2015, p. 1).

One of the reasons for the insistence on the suppression of lower-level selection is the assumption that lower-level selection would oppose the higher level of selection and, being stronger, prevent a response to higher-level selection. Thus, in this view, lower-level selection must be starved of genetic variation by relatedness in order for higher-level selection to thrive. It is under this set of assumptions that seemingly all critics of the holobionts have been operating (e.g., Moran and Sloan 2015; Douglas and Werren 2016). In contrast, we argue this viewpoint is neither necessary nor appropriate, and does not reflect the multilevel hierarchical models that we appeal to. On our type of models, the lower-level selection may complement-and in relevant cases, does in fact amplify-the higher-level selection forces. Moreover, as argued in Wade (2016) IGEs constitute a source of genetic variation that is often not accessible to individual-level selection.
Developments in contemporary multilevel selection theory (Wade 2014, 2016; Goodnight 2015, 2016) show, both theoretically and empirically, that, when higher levels of selection act on indirect genetic effects, the genetic response to group or community selection is qualitatively different from the response to individual selection. This is owing in large part to the difference between heritability as defined for individuals under the genic selection view and heritability of a group trait in multilevel selection theory (Bijma and Wade 2008; Wade 2016). The effectiveness of community selection experiments (Goodnight 1990a, b) without any of the constraints on lower-level selection assumed by the evolutionary-transitions approach, indicates, at the very least, that the heritability of community-level traits and selection among communities may play a significant role in the evolution of holobionts.

The adoption of the hierarchal evolutionary transitions theory of Maynard Smith and Szathmary would be inappropriate in these circumstances. We showed above that interspecific epistasis $(e \neq 0)$ is sufficient to establish a holobiont as a unit of selection with respect to its characteristics as an interactor and any non-zero degree of vertical transmission $(v>0)$ establishes a holobiont as a unit of selection in terms of a reproducer. The definition of the holobiont does not include the requirement that the holobiont be the single unit or level of selection in operation at a given evolutionary time. On the contrary, the advocates appeal directly to multilevel selection theory under which multiple units at multiple levels are simultaneously under selection (Dupré 2010, 2012; Dupre and O'Malley 2013; Theis et al. 2016; Roughgarden et al. 2017; Lloyd 2018). Differently put, interspecific epistasis $(e \neq 0)$ and a non-zero degree of vertical transmission $(v>0)$ do not guarantee that selection at the level of the holobiont will predominate. However, Drown et al. (2013) showed that whenever genetic modifiers of the degree of vertical transmission existed and there was positive interspecific epistasis $(e>0)$, that the genetic variants favoring a higher degree of vertical transmission hitchhiked on the spread of the epistatic mutations, creating a feedback process that enhances higher-level selection (Sober and Wilson 1998).

Douglas and Werren (2016, p. 4) argue against the holobiont/hologenome view when they conclude that, "established evolutionary methods are fully able to address multilevel selection [citing Maynard Smith and Szathmary, and West et al.] without the constraints imposed by the specific assumptions of the hologenome concept." But, because multilevel selection theory with synergistic epistasis and indirect genetic effects has not yet been fully translated into the holobiont context, we cannot agree with this claim.

Douglas and Werren (2016) further object to the treatment in the holobiont/hologenome literature of the host microbe association as a single unit of selection because 
there are symbionts that reduce host fitness and because there can be conflict between symbionts. However, in ecological communities, like the holobiont, it has long been understood that (Thompson 1994, p. 286), "studies of pairwise interactions alone are insufficient for understanding the evolution of interactions in general and the coevolutionary process in particular." Indirect ecological effects are common in ecological communities of which the holobiont is an example. In an ecological as opposed to a genetic context, indirect effects occur when more than two species interact and one species alters the effect that another species has on a third species (Strauss 1991; Stanton 2003).

Moreover, direct interactions between a pair of species may not be representative of the population dynamics when the indirect effects of other community members are considered (Stanton 2003). As we stated above, the hologenome concept does not assume that all elements of the holobiont are cooperative; rather, it includes conflict among its parts, though incorporated into a whole (see Dupré 2013; Theis et al. 2016; Roughgarden et al. 2017; Lloyd 2018). And, it is well established that vertically transmitted parasites, which may harm hosts when considered alone, may serve as indirect mutualists when they exclude more virulent horizontally transmitted parasites (Lively et al. 2005). Coevolution in the context of these three-species communities (host, mild pathogen, virulent pathogen) bears conspicuous similarity to nuclear gene models of the cost of resistance in plants to herbivores or the cost of resistance in bacteria to antibiotics.

In the holobiont, as in ecological communities in general, symbiont abundances are determined by complex webs of interactions. These in turn determine holobiont (i.e., community) properties such as diversity and stability (Miller and terHorst 2012). Identifying and quantifying indirect ecological effects is a major issue in community ecology, and connecting indirect ecological effects and indirect genetic effects with multilevel selection theory is a major concern of community genetics. This is, in part, why we believe that a theory for the evolution of holobionts will emerge from community genetics instead of gene-centric, species-centric evolutionary theory.

\section{Holobionts and the Logic of Research Questions}

The biases of the gene-centric view toward single-gene effects, the ubiquity of conflict between the evolutionary interests of different genomes, and the supremacy of lower-level selection direct the research questions asked, the data gathered, and the interpretations rendered. The "gene's-eye" perspective rules out consideration of the holobiont as a level or unit of selection except under stringent conditions, which include restraining lower-level selection. The multilevel selection perspective is different. It places a greater emphasis on determining whether or not a holobiont has the properties or features necessary to function as one unit of selection among many. It emphasizes fitness interaction, particularly interspecific epistasis, as a means of characterizing a property of the holobiont as an interactor that cannot, statistically speaking, be attributed to its component species. It also focuses on transmission mode, since any degree of vertical transmission establishes the holobiont as a unit of selection with respect to the reproducer criterion.

In order to understand gene function, geneticists have a long-standing practice of causing errors in genes by the application of mutagens, gene knockouts, interfering RNA, and so on. If we understand gene function by causing errors in genes through gene knockouts, what is the methodological analogy in the study of the function of gene combinations? We suggest that the relevant analogy is creating novel gene combinations by disrupting those established in nature and seeing whether any functions, particularly those related to fitness, are diminished or absent. The yeast two-hybrid system (Fields and Song 1989) originally designed for studying protein-protein interactions is one commonly used method in molecular biology for studying physiological epistasis. This methodology has not been part of the genic-selectionists' toolbox or reasoning. Instead, they use the single-gene components of gene combinations to "discover" evidence of "gene conflict," not evidence for or against coevolution. As a matter of theoretical practice (e.g., Rice 2013), they anticipate that the parts of a whole will be in conflict with one another rather than seeing them as parts of a whole that coevolved owing to epistasis, i.e., with fitness more than the sum of its parts. The myriad of functional protein-protein interactions discovered using the yeast two-hybrid system in the decade after its development (Young 1998) is empirical evidence that a gene-centric view of adaptive evolution is incorrect within species and is unlikely to characterize the more complex interactions of genes across genomes in the holobiome.

As an alternative to the gene-centric approach, we can study how a gene combination falls apart when we break up good combinations and reassemble them in combinations deleterious for fitness together. And, we can infer gene coevolution from the bad gene combinations, because they reduce function or fitness, just as we infer gene function from mutant genes that are poorly functioning. We don't say my lamp stopped working because the light bulb is cheating on the switch! Analogously, we argue that it is inappropriate to tell adaptive stories about genetic parts separately, when the whole is the functional level at stake. We can see this distinction between the gene'seye approach and the community genetics approach more 
clearly by examining the Logic of Research Questions as applied to the different conceptual programs. This involves posing relevant research questions for each research program and considering the possible and responsive answers to them under that research program.

On the gene's-eye approach, the research questions involve looking for conflict and cheating among parts of a genetic system, as we can see in Set 1 .

\section{Set 1: Genic Selection Research Questions}

Let's examine how genic selectionists approach a system that they want to understand. They tend to ask research questions like the following:

"Who is outcompeting whom? Who is cheating on whom? Who benefits at the cost of whom? Who wins this evolutionary conflict? What is the lowest level entity that can be treated as an evolving population, and what are its evolutionary interests? Should a gene cheat its relatives as much as it cheats nonrelatives?"

Possible and responsive answers to these questions include:

A Cheaters arise within a population and spread.

A There must be many policing mechanisms, because otherwise there would be more cheaters.

A Females are cheating on males.

A Males are cheating on (or sterilizing) females.

A Maternal evolutionary interests are in conflict with those of offspring.

A Mitochondrial genome interests are in conflict with those of the nuclear genome.

(Ehrlich and Ravens 1964; Williams 1966; Futuyma 1998, Rice 2013; Bronstein 2015; Jones et al. 2015)

\section{Set 2: Genic Selection Research Questions Related to the Holobiont}

Now, let's examine how genic selectionists approach a holobiont that they want to understand. They tend to ask research questions similar to those in Set 1:

"Who is outcompeting whom? Who is cheating on whom? Who benefits at the cost of whom? Who wins this conflict? What is the lowest level entity that can be treated as an evolving population, and what are its evolutionary interests?"

Possible and responsive answers to these questions include:

A Microbes are cheating on hosts.

A Hosts are cheating on microbes.
A Vertically transmitted symbionts distort the sex ratio towards females, creating conflict with the nuclear genome.

A. Mutualisms are evolutionarily unstable owing to the genomic conflict that develops when cheaters arise in either the host or its symbionts.

A There must be many policing mechanisms, because otherwise more cheaters would be observed in natural mutualistic systems.

(Bronstein 2015; Jones et al. 2015; Moran and Sloan 2015; Szathmary 2015; Burt and Trivers 2006; Douglas and Werren 2016; Queller and Strassman 2016).

Consider the RQ, "What is the lowest level entity that can be treated as an evolving population, and what are its evolutionary interests?" The question posed here is a version of the "parsimony" method, advocated originally by GC Williams (1966) to avoid the perils of group selection. Much later, Williams (1990, p. 504) admitted that his "parsimony" method was not, in fact, the best method to deal with group selection debates. In his review of Lloyd (1988), he instead endorses a multilevel selectionist approach that "makes more sense than any other I have seen."

Nevertheless, Moran and Sloan (2015, p. 6) appeal to Williams' (1966) view arguing that holobionts undergo selection much like the "Early and oversimplified views of group selection...[which] failed to recognize that population-level adaptations are unstable under most circumstances, due to susceptibility to invasion by selfish individuals (... Williams 1966)." Similarly, Douglas and Werren (2016) invoke both Williams' parsimony concept and his averaging reasoning about epistasis (see Williams 1966, p. 56).

But what is a viable research alternative to the traditional gene-oriented approach? As hinted above, in studying coevolution, we engage different research questions that yield a different set of possible and responsive answers:

\section{Set 3: Coevolutionary Community Genetics Research Questions}

Let's examine how community geneticists approach a holobiont that they want to understand. They tend to ask research questions like the following:

"What is a well-functioning, interspecific gene combination? What is interspecific epistasis and how can it be measured to determine whether or not the holobiont is an interactor? What adaptive function does a gene combination across host and microbe have to have for the holobiont to establish it as a beneficiary? What happens with poor gene combinations, when they appear through mutation, recombination, or hybridi- 
zation? What is the level of vertical transmission and/ or partner choice necessary to establish a holobiont as a reproducer?"

Possible and responsive answers to these questions include:

A Well-functioning gene combinations are coadaptations with the holobiont as beneficiary.

A This trait or coadaptation is the specific function of this gene combination appearing across two or more populations/species.

A If coadapted populations evolve separately and cross, they produce inviable hybrids or chimeras.

A This host gene provides a good background for this particular microbe gene and its reproduction, and together they produce this interactor which has a particular function interacting with the environment. (In the mathematical description above, we called this interspecific epistasis, e.)

A This microbe is a particularly good background for this host gene.

A This microbe gene is a good background for this host gene and its reproduction, and together they produce this interactor which has a particular function interacting with the environment. (In the mathematical description above, we called this interspecific epistasis, e.)

A Or both of the above, evolving a mutualism which reproduces itself (above random in proportion to the degree of vertical transmission, $v$, which is a continuum).

A When symbionts' genes are bad combinations with the host genes, or vice versa, they do not build up associations; the combination dissipates, because there is no or limited reproduction of malfunctioning holobionts. Once they are rare, there is no evolutionary interaction, either.

(Birky 2001; Odling-Smee et al. 2003; Wade and Goodnight 2006; Brandvain et al. 2007; Wade 2007, 2016; Brandvain and Wade 2009; Bright and Bulgheresi 2010; Brucker and Bordenstein 2013; Drown et al. 2013; Bordenstein and Theis 2015; Roughgarden et al. 2017)

Epistatic selection on individuals creates nonrandom genetic associations. The same type of associations between host and symbiont genes are set up by selection acting on holobionts when there is interspecific epistasis or pleiotropy.

What are not adequate answers to the coevolution RQs above are the answers like: "one gene is cheating on the other gene" or "one type of organism is cheating on the other type of organism," because these are nonresponsive to the specific questions at hand. Differently put, the questions ask about well-functioning gene combinations, which have, by definition, an epistatic component that does not belong to the host or to the symbiont. Cheaters impose a $[+,-]$ epistatic interaction on a holobiont, and epistatic selection does not increase the frequency of such associations but rather diminishes them. Furthermore, by diminishing the frequency of the specific host genotypes, the biotic environment on which they thrive, cheating symbionts reduce resource abundance for their own offspring. Although they seem to offer an answer to some of the RQs posed in Set 3, we argue that such an answer to this case is not best conceived as a case of "cheaters," but rather as a case of "losers" (i.e., poor gene combinations).

Moran and Sloan (2015) advocate the theoretical and experimental study of selection acting on holobionts as "composite entities," but we argue that their LRQ as expressed in Set 2 limits the nature of their questions and what are considered responsive answers to them. In Set 3, we have proposed an alternative that is backed by a large body of theoretical and experimental work devoted to investigating how selection acts on composite entities in genetically structured populations.

Consider the following metaphor: If the switch is broken or the light bulb is broken, a lamp does not work. If we say the broken switch is cheating on the light bulb, we are imbuing the switch with an inappropriate property from the point of view of the functional structures involved in the research question. The analogous categories under the good gene combinations are a functioning switch and functioning light bulb; all other combinations of switch and bulb are poor combinations with lower fitness. Functioning combinations increase in frequency as evidenced by positive interspecific linkage disequilibrium (ILD). Conversely, combinations bad for the fitness of the whole occur less frequently than random. Negative interactions that lower the fitness of the whole do not reproduce themselves, that is, neither defective part spreads. They are not cheaters, they are losers.

Note also, the above are adequate explanations for the coevolutionary research question, but not responsive answers to the research question, "Who is cheating on whom?" or "What is the lowest-level entity that can be treated as an evolving population, and what are its evolutionary interests?" from Sets 1 or 2.

\section{The Case of the Vibrio-Squid Symbiosis}

From the genome conflict LRQ, extreme partner fidelity, like vertical transmission, can reduce genome conflict but not eliminate it. As Moran and Sloan (2015, pp. 6-7) put it, "even when symbionts are vertically inherited and more readily regarded as part of the host genetics than as part of the environment, conflicts are rampant" (our emphasis). For that reason, the bobtail squid-Vibrio fishcheri symbiosis 
poses a significant problem for the general dismissal of holobiont dynamics in nature. In this symbiosis like many others, all host squid are born without bacteria and must acquire them from the environment. That is, none of the bacteria are vertically inherited, yet they "retain features (luminescence) that benefit hosts" (2015).

Because Moran and Sloan see the squid as at risk of being "invaded" by bacteria interested in taking over the host, the retention of host-beneficial traits by the symbiont poses a problem. The solution, under the genic/cheater Set 2 LRQ, is to propose that, "hosts have evolved effective policing mechanisms that prevent 'selfish' symbionts from invading and spreading" (Moran and Sloan 2015, p. 7).

Our perspective on this vibrio-squid symbiosis under the LRQ of community genetics in Set 3 is different. The association between squid and symbiont has to be reestablished each generation. The biology of this process suggests that there is a strong asymmetry in coevolution, whereby adaptation on the part of the squid to use the symbiont has been significantly greater than reciprocal adaptation by the symbiont to the squid.

Consider the life history of the squid. The adult female squid, Euprymna scolopes, lives approximately one year and is iteroparous, laying several clutches of eggs. After laying a clutch, a female covers it with sand but provides no other parental care (McFall-Ngai 1999). The young are born without symbionts but begin obtaining them from seawater shortly after hatching. Vibrio fisheri cells typically represent less than one-tenth of one percent of the bacterial cells in seawater, but host adaptations interact with the symbiont to ensure that it alone becomes predominant within the squid. This process of "symbiont recognition," which functions to diminish or eliminate bacteria other than V. fisheri, is analogous to mate recognition, which functions to diminish or eliminate hybridization between heterotypic individuals. This type of "partner choice" at the species level is different from, and could occur without causing, the genotypic matching necessary to create ILD (see above). However, mutant $V$. fischeri strains defective in light production are outcompeted and do not persist in the light organ of the squid (Nyholm and McFall-Ngai 2004). This process could create ILD if squid genotypes differed in the efficiency of this process, but this has not been shown. The ciliated epithelia of a squid's nascent light organ are essential to successful colonization by free-living $V$. fisheri cells, although after colonization, the symbionts induce the loss of the cilia that promote colonization, preventing inclusion of additional $V$. fisheri cells (Nyholm et al. 2002; Nyholm and McFall-Ngai 2004). This makes Vibrio colonization a one-time event during early squid development.

The initial colonization process establishes a symbiont population for the lifetime of the host. In addition, the numbers of colonists entering a host's light organ is very small such that "only one or two cells of $V$. fischeri enter each of six internal epithelium-lined crypts present in the developing light organ" (Wollenberg and Ruby 2009, p. 193). This is a smaller bottleneck of colonists than the bottleneck experienced by vertically transmitted mitochondria colonizing an unfertilized egg in most species of animals (Birky 2001; Rand 2001). The small number of founders grows rapidly to a much larger population, which then initiates the quorumsensing bioluminescent features of the squid. Each day, a squid expels 95 percent or more of its symbiont population but does not take in any additional symbionts. Although some studies suggest that this daily expulsion results in "an increased likelihood that subsequent generations of squids will be successfully inoculated," (McFall-Ngai 1999, p. 241) there is as yet no evidence of such enrichment.

Turning to the symbiont, populations of bioluminescent $V$. fischeri consist of free-living cells, sediment-associated biofilms, and host-associated mutualists. Even the latter cells "alternate between growth within their hosts and prolonged survival in aquatic habitats" (Yildiz and Visick 2009). Wollenberg and Ruby (2009) hypothesize that there are growth trade-offs between the symbiont-associated and free-living seawater environments. The more common and more heavily populated environment is nonhost associated. ${ }^{3}$ For example, Jones et al. (2007, p. 320; our emphasis) found that, "members of the Vibrionaceae still constitute a large proportion of the bacterioplankton community in the areas we were able to sample, with or without the presence of squid hosts."

Thus, although every individual squid has bioluminescent symbionts, the vast majority of the symbiont population is not dependent upon or found in association with squid. In the terminology of our model ("Evolution in Biotic and Abiotic Environments" section above), the frequency of non-symbiont harboring squid is near zero (host $\mathrm{f}_{3} \sim 0$ ) but the frequency of free-living, nonhost associated $V$. fischeri is very high (symbiont $\mathrm{f}_{3} \sim 1$ ). Moreover, free-living strains of $V$. fischeri have been shown to grow under a wider variety of environmental conditions than symbiotic strains. Chavez-Dozal et al. (2013, p. 557) found that, "free-living strains are considerably more resistant to grazing pressure than symbiotic strains" and suggested that, "host selection may compromise the fitness of [host-associated] $V$. fischeri strains that are more amenable to a stable (and predatorless) environment compared to the external environment." Given the greater abundance and fitness of free-living symbionts, which are the source of the host-associated symbiont populations, it is reasonable to expect that gene flow

\footnotetext{
${ }^{3}$ Note that the squid-related vibrio are an insignificant portion of the total vibrio population, since the squid release 50,000 vibrio per day, while it is estimated that $30-150$ million free-living vibrio cells pass over the mantle of the squid every day.
} 
limits adaptation of $V$. fischeri to the host-associated, squid environment.

Given the predominately one-sided nature of adaptation in this example, we suggest that the vibrio-squid association be called a "demibiont" instead of a "holobiont." This new terminology acknowledges and characterizes the case of primary concern to Moran and Sloan (2015), wherein a host adapts to the biotic environment of the selected and associated symbiont in the same way as it may exhibit habitat choice and adapt to an abiotic environment. Although we agree with Moran and Sloan (2015) on this point in this specific case, we do not agree that, in general, adaptation to a biotic environment is equivalent to adaptation to an abiotic environment, for reasons given in the "Evolution in Biotic and Abiotic Environments" section above. Nor, as we argued in that section, do we believe a priori that most holobionts are or have been shown to be demibionts. It would be of great interest to know what fraction of host-associated microbes are demibionts, mutualists, or opportunists.

We emphasize, however, that our reasons for both agreeing with Moran and Sloan in the vibrio-squid case but disagreeing in general derive from our pursuit of the LRQ of community genetics Set 3 instead of the LRQ of genic/ cheater Set 2. From the perspective of genome conflict (LRQ Set 2), selfish, nonluminescent bacteria would invade host squid if not for a stringent policing mechanism of the host which results in luminescence being maintained by the bacteria for the benefit of its host. The biology of the vibriosquid colonization process shows that "selfish" bacteria are not invading a passive host nor is the host selecting among or "policing" passive bacterial genotypes. It is also not the case that the luminescence is maintained as a feature of the symbiont "for the benefit of the host." In phylogenetic studies of the Vibrionaceae, Vibrio species, including V. fisheri, are derived from bioluminescent, nonhost-associated ancestors (Sawabe et al. 2013). Bioluminescence in nonhost-associated bacteria is an adaptation to resource scarcity in the deep sea environment. It results in glowing bacteria being taken into the nutrient-rich environments of the guts of marine fish and arthropods (i.e., they are eaten) "where they survive digestion and gain effective means for growth and dispersal" (Zarubin et al. 2012). There is no conflict over bioluminescence between the squid and its symbiont as suggested by the LRQ Set 2 research questions. And, although a squid appears to provide a superb environment for the growth of $V$. fischeri populations, the small founding numbers severely reduce genetic variation, and relaxed selection of the within-host environment results in lowered fitness of the host-associated strains when they are released from squid and subsequently compete with nonhost-associated and free-living strains. Rather than see the loss of fitness of host-associated $V$. fischeri populations as the result of genomic conflict, the complex process of colonization, population growth, and expulsion might be better seen as each squid performing a "mutation-accumulation" (Halligan and Keightley 2009) experiment on its symbiont population over its lifetime.

Overall, we propose that the study of holobionts is best served by seeing holobionts as distributed along a continuum of fitness interactions and partner fidelities. The overall strategy of holobiont critics has been to take extreme versions of holobionts along the continua, and say "these are uncommon," and conclude therefore that there is nothing new here to be understood. This strategy is analogous to only studying eusocial organisms and concluding that, since they are uncommon, therefore all other forms of sociality, including intermediate forms, are uncommon. We will be the first to say that the euholobiont is uncommon, but insist that regular holobionts, in between demibionts and euholobionts, are nearly universal. Moreover, the conceptual approach to understanding them ought to be different from the gene-centered, species-centered perspective founded on the principle of genome conflict.

Moran and Sloan (2015, p. 7; emphasis in original) ask the important question, "What Is the Null Hypothesis?" And after acknowledging that, "Many features of eukaryotes... cannot be understood without taking into account microbial associates," they ask, "but how should we formulate our questions and hypotheses?" We agree that this is the essential issue at stake, but point out that there is more than one approach, each with a different LRQ, to answering this question. Here we have contrasted the two approaches with respect to a specific case of a host and its associated symbiont. Moran and Sloan (2015, p. 7; emphasis in original) argue that, "the wrong approach is to start with the assumption that associated organisms have evolved to function as a cooperative unit and that the task is simply to characterize mutually beneficial adaptations." And they advance the view that, "A more parsimonious approach is to adopt the null hypothesis that interacting lineages have not evolved exceptional hologenome-selected traits, and to test specific hypotheses regarding such traits."

Their argument is advanced in terms of the merits of simplicity or parsimony, just as Williams had argued 50 years ago against group selection, in an argument that he later abandoned when pressed in a real-life case (Williams 1990). We agree with Moran and Sloan (2015, pp. 7-8) in their call for "careful wording that does not invoke dubious evolutionary mechanisms." We have argued that what is seen as a dubious evolutionary mechanism depends upon the prior commitment to a specific LRQ. 


\section{Conclusions}

In the summary of their case against holobionts, Douglas and Werren (2016, p. 4) argue that contemporary understanding "identifies the dominant processes shaping the evolutionary trajectory of vertically transmitted microorganisms to operate at levels of selection lower than the association." We have discussed our concern that they are not utilizing appropriate hierarchical community genetics models applicable to holobionts. We have also addressed their assumption that coevolution of host and symbionts requires that selection occurs exclusively or primarily at the holobiont level. Our proposal is rather that the holobiont is one among many possible levels of selection operative in the evolutionary process, and needs to be taken into account when giving an evolutionary account of the association between a host and its microbes. We have argued further that evolutionary transitions theory après Maynard Smith and Szathmary may not be an appropriate category of selection processes or dynamics for understanding these cases. Because we are interested in the origins of different transmission modes and in the evident polymorphism among transmission modes in some host-symbiont associations, we would not limit the study of holobionts to those strictly vertically transmitted communities. That is, the restriction of study to "particular host-symbiont pairs with high partner fidelity and not to the entire host-microbiome, which includes diverse interactions and fidelities of association" (Douglas and Werren 2016, p. 4; see also Moran and Sloan 2015; Doolittle and Booth 2017) is a restriction that is unnecessary under our multilevel, community genetics approach.

The kind of selection assumed to be operating in the holobiont case on our models is one involving epistasis at the trait or genetic level, and not one in terms of suppression of a lower level in favor of any higher level, and contrary to the models the opponents of holobionts cite as appropriate in their papers. Douglas and Werren write in their conclusion that the holobiont/hologenome approach "focuses on one level of selection (the holobiont), and as a result it is concerned with cooperative and integrative features of hostmicrobe systems to the exclusion of other kinds of interactions, including antagonism among microorganisms and conflicts between host and microbial partners." This is a mischaracterization of the literature. Antagonism and conflicts are included between hosts and between microbial partners (Dupré 2013; Dupre and O'Malley 2013; Theis et al. 2016; Roughgarden et al. 2017; Lloyd 2018). Hosts can become symbiotic occasionally with pathogenic organisms, e.g., $E$. coli (Lively et al. 2005). Because the genic level LRQ (Set 2 ), assumed by the opponents of holobionts, only admits certain combinations as plausible or responsive answers to the selfish gene picture, it has led to these mistaken conclusions dismissing antagonistic relationships.

The most significant results of this article include the proposal of genetics models that clarify the self-limiting nature of cheating, and the runaway process dynamics of mutualism. We have argued that these models falsify the many claims about holobionts that have been made concerning their limitations due to cheaters, i.e., organisms or genes that, in their self-interest, foil the adaptive process of a jointly adaptive state of a higher-order mutualism. Moreover, misunderstandings due to the failure to distinguish between the evolutionary interactor and evolutionary reproducer have stymied progress in understanding the holobiont and its evolutionary role (Roughgarden et al. 2017; Lloyd 2018). In addition, there has been a misunderstanding of the dynamics of multilevel selection itself (Wade 2007; Drown and Wade 2014). Our models indicate that mutualisms would be expected to be more common in the natural world. Despite the expectation, on the genic-level cheater theory, that few mutualisms would be found, and more than a few cheaters, actual well-defined cheaters have yet to be found in nature (Jones et al. 2015; see Bronstein 2015). Moreover, cases of parasitism transitioning to mutualism are not possible under genomic conflict theory but are common in some clades (Bronstein 2015). ${ }^{4}$ In sum, we take all of this evidence from nature as a good sign for our models of mutualisms and holobionts.

Acknowledgments We would like to thank the Biology Studies Reading Group at Indiana University's History and Philosophy of Science and Medicine Department as well as the Biological Interest Group of the Minnesota Center for Philosophy of Science at the University of Minnesota for comments and advice, as well as Lynda Delph, Ryan Ketcham, and Ryan O'Loughlin for their helpful comments. Support was provided to MJW by a grant from the John Templeton Foundation, sabbatical funding from Indiana University, and a fellowship from the Wissenschaftskolleg in Berlin.

Open Access This article is distributed under the terms of the Creative Commons Attribution 4.0 International License (http://creativeco mmons.org/licenses/by/4.0/), which permits unrestricted use, distribution, and reproduction in any medium, provided you give appropriate credit to the original author(s) and the source, provide a link to the Creative Commons license, and indicate if changes were made.

\section{References}

Abrams PA (1986) Is predator-prey coevolution an arms race? Trends Ecol Evol 1(4):108-110. https://doi.org/10.1016/01695347(86)90037-6

Abrams PA (2000) The evolution of predator-prey interactions: theory and evidence. Annu Rev Ecol Syst 31(1):79-105

$\overline{4}$ This seems to be possible in Yamamura's models $(1993,1996)$. 
Adams KL, Song K, Roessler PG, Nugent JM, Doyle JL et al (1999) Intracellular gene transfer in action: dual transcription and multiple silencings of nuclear and mitochondrial cox2 genes in legumes. Proc Natl Acad Sci USA 96(24):13863-13868

Akcay E (2015) Evolutionary models of mutualism. In: Bronstein JL (ed) Mutualism. Oxford University Press, Oxford/New York, pp 57-76

Arnold AE, Miadlikowska J, Lindsay Higgins K, Sarvate SD, Gugger $P$ et al (2009) A phylogenetic estimation of trophic transition networks for ascomycetous fungi: are lichens cradles of symbiotrophic fungal diversification? Syst Biol 58(3):283-297

Bijma P (2014) The quantitative genetics of indirect genetic effects: a selective review of modelling issues. Heredity 112(1):61-69. https://doi.org/10.1038/hdy.2013.15

Bijma P, Wade MJ (2008) The joint effects of kin, multilevel selection and indirect genetic effects on response to genetic selection. J Evol Biol 21(5):1175-1188. https://doi.org/10.111 $1 / \mathrm{j} .1420-9101.2008 .01550 . x$

Birky CWJ (2001) The inheritance of genes in mitochondria and chloroplasts: laws, mechanisms, and models. Ann Rev Gen 35:125-148

Bordenstein SR, Theis KR (2015) Host biology in light of the microbiome: ten principles of holobionts and hologenomes. PLoS Biol 13(8):e1002226. https://doi.org/10.1371/journal.pbio.1002226

Bosch TCG, Miller DJ (2016) Introduction: the holobiont imperative. In: Bosch TCG, Miller DJ (eds) The holobiont imperative: perspectives from early emerging animals. Springer Vienna, Vienna, pp 1-10. https://doi.org/10.1007/978-3-7091-1896-2_1

Brandvain Y, Wade MJ (2007) The evolution of competition and policing: opposing selection within and among groups. BMC Evol Biol 7(1):203. https://doi.org/10.1186/1471-2148-7-203

Brandvain Y, Wade MJ (2009) The functional transfer of genes from the mitochondria to the nucleus: the effects of selection, mutation, population size and rate of self-fertilization. Genetics 182:1129-1139

Brandvain Y, Barker MS, Wade MJ (2007) Gene co-inheritance and gene transfer. Science 315:1685

Bright M, Bulgheresi S (2010) A complex journey: transmission of microbial symbionts. Nat Rev Microbiol 8(3):218-230. https:// doi.org/10.1038/nrmicro2262

Brodie ED III, Brodie ED Jr (1999) Predator-prey arms races: asymmetrical selection on predators and prey may be reduced when prey are dangerous. BioScience 49(7):557-568. https://doi. org/10.2307/1313476

Bronstein JL (ed) (2015) Mutualism. Oxford University Press, Oxford/ New York

Brucker RM, Bordenstein SR (2013) The hologenomic basis of speciation: gut bacteria cause hybrid lethality in the genus nasonia. Science 341(6146):667-669. https://doi.org/10.1126/science.12406 59

Burt A, Trivers R (2006) Genes in conflict: the biology of selfish genetic elements. Harvard University Press, Cambridge http:// www.hup.harvard.edu/catalog.php?isbn $=9780674027220$

Bustamante C, Keller D, Oster G (2001) The physics of molecular motors. Acc Chem Res 34(6):412-420

Chavez-Dozal A, Gorman C, Erken M, Steinberg PD, McDougald D, Nishiguchi MK (2013) Predation response of Vibrio fischeri biofilms to bacterivorus protists. Appl Environ Microbiol 79(2):553-558

Crespi BJ (2004) Vicious circles: positive feedback in major evolutionary and ecological transitions. Trends Ecol Evol 19(12):627-633. https://doi.org/10.1016/j.tree.2004.10.001

Darwin C (1866) On the origin of species, 4th edn. Murray, London

Doolittle WF, Booth A (2017) It's the song, not the singer: an exploration of holobiosis and evolutionary theory. Biol Philos 32(1):524. https://doi.org/10.1007/s10539-016-9542-2
Douglas AE, Werren JH (2016) Holes in the hologenome: why hostmicrobe symbioses are not holobionts. MBio 7(2):e02099-15. https://doi.org/10.1128/mBio.02099-15

Drown DM, Wade MJ (2014) Runaway coevolution: adaptation to heritable and nonheritable environments. Evolution 68(10):30393046. https://doi.org/10.1111/evo.12470

Drown DM, Zee PC, Brandvain Y, Wade MJ (2013) Evolution of transmission mode in obligate symbionts. Evol Ecol Res 15(1):43-59

Dupre J (2012) Post-genomic darwinism. In: Dupre J (ed) Processes of life: essays in the philosophy of biology. Oxford University Press, Oxford/New York, pp 143-160

Dupré J (2010) The polygenomic organism. Sociol Rev 58(s1):19-31. https://doi.org/10.1111/j.1467-954X.2010.01909.x

Dupré J (2013) I—living causes. Aristot Soc Suppl 87(1):19-37. https ://doi.org/10.1111/j.1467-8349.2013.00218.x

Dupre J, O'Malley MA (2013) Varieties of living things: life at the intersection of lineage and metabolism. In: Normandin S, Wolfe CT (eds) Vitalism and the scientific image in post-enlightenment life science, 1800-2010. History, philosophy and theory of the life sciences. Springer Netherlands, Dordrecht, pp 311-343. www.springer.com/us/book/9789400724440

Ehrlich P, Raven PH (1964) Butterflies and plants: a study in coevolution. Evolution 18:586-608

Fields S, Song O (1989) A novel genetic system to detect proteinprotein interactions. Nature 340(6230):245-246. https://doi. org/10.1038/340245a0

Futuyma DJ (1998) Evolutionary biology, 3rd edn. Sinauer, Sunderland Godfrey-Smith P (2009) Darwinian populations and natural selection. Oxford University Press, Oxford

Godfrey-Smith P (2012) Darwinian individuals. In: Bouchard F, Huneman P (eds) From groups to individuals: perspectives on biological associations and emerging individuality. Harvard University Press, Cambridge, pp 17-36

Goodnight CJ (1990a) Experimental studies of community evolution II: the ecological basis of the response to community selection. Evolution 44(6):1625-1636. https://doi.org/10.2307/2409342

Goodnight CJ (1990b) Experimental studies of community evolution I: the response to selection at the community level. Evolution 44(6):1614-1624. https://doi.org/10.1111/j.1558-5646.1990. tb03850.x

Goodnight CJ (2013) Defining the individual. In: Bouchard F, Huneman P (eds) From groups to individuals: evolution and emerging individuality. MIT Press, Cambridge, pp 37-52

Goodnight CJ (2015) Multilevel selection theory and evidence: a critique of gardner, 2015. J Evol Biol 28(9):1734-1746. https://doi. org/10.1111/jeb.12685

Goodnight CJ (2016) On the effectiveness of multilevel selection. Behav Brain Sci 39:e99. https://doi.org/10.1017/S0140525X1 5001053

Griesemer JR (2000) The units of evolutionary transition. Selection $1-3: 67-80$

Griesemer JR (2016) Reproduction in complex life cycles: toward a developmental reaction norms perspective. Philosophy of Science 83:803-815

Halligan DL, Keightley PD (2009) Spontaneous mutation accumulation studies in evolutionary genetics. Annu Rev Ecol Evol Syst 40(1):151-172. https://doi.org/10.1146/annurev.ecols ys.39.110707.173437

Hull DL (1980) Individuality and selection. Annu Rev Ecol Syst 11(1):311-332. https://doi.org/10.1146/annurev.es.11.11018 0.001523

Jones BW, Maruyama A, Ouverney CC, Nishiguchi MK (2007) Spatial and temporal distribution of the Vibrionaceae in coastal waters of Hawaii, Australia, and France. Microb Ecol $54(2): 314-323$ 
Jones EI, Afkhami ME, Akçay E, Bronstein JL, Bshary R et al (2015) Cheaters must prosper: reconciling theoretical and empirical perspectives on cheating in mutualism. Ecol Lett 18(11):1270-1284. https://doi.org/10.1111/ele.12507

Ketcham R (2018) Task allocation and the logic of research questions: how ants challenge human sociobiology. Biol Theory. https://doi. org/10.1007/s13752-018-0308-8

Kiester AR, Lande R, Schemske DW (1984a) Models of coevolution and speciation in plants and their pollinators. Am Nat 124(2):220-243. https://doi.org/10.1086/284265

Kiester AR, Lande R, Schemske DW (1984b) Models of coevolution and speciation in plants and their pollinators. Am Nat 124(2):220-243. https://doi.org/10.1086/284265

Leung TLF, Poulin R (2008) Parasitism, commensalism, and mutualism: exploring the many shades of symbioses. Vie et Milieu 58(2):107-115

Lively CM, Morran LT (2014) The ecology of sexual reproduction. J Evol Biol 27(7):1292-1303

Lively CM, Clay K, Wade MJ, Fuqua C (2005) Competitive coexistence of vertically and horizontally transmitted parasites. Evol Ecol Res. http://agris.fao.org/agris-search/search.do?recor $\mathrm{dID}=\mathrm{US} 201301061920$

Lloyd EA (1988) The structure and confirmation of evolutionary theory. Princeton University Press, Princeton

Lloyd EA (2001) Units and levels of selection: an anatomy of the units of selection debates. In: Krimbas CB, Paul DB, Beatty J, Singh RS (eds) Thinking about evolution: historical, philosophical, and political perspectives. Cambridge University Press, Cambridge, pp 267-291

Lloyd EA (2015) Adaptationism and the logic of research questions: how to think clearly about evolutionary causes. Biol Theory 10(4):343-362. https://doi.org/10.1007/s13752-015-0214-2

Lloyd EA (2017) Units and levels of selection. In: Zalta EN (ed) Stanford encyclopedia of philosophy (Summer 2017 edn). https:// plato.stanford.edu/archives/sum2017/entries/selection-units/

Lloyd EA (2018) Holobionts as units of selection: holobionts as interactors, reproducers, and manifestors of adaptation. In: Gissis Sb, Ehud L, Ayelet S (eds) Landscapes of collectivity in the life sciences. Vienna series in theoretical biology. MIT Press, Cambridge. https://www.researchgate.net/publicatio n/312167080

Lloyd EA, Oreskes N (2018) Climate change attribution: when is it appropriate to accept new methods? Earth's Future 6(3):311325. https://doi.org/10.1002/2017EF000665

May RM (1971) Stability in multi-species community models. Math Biosci 12:59-79

McFall-Ngai MJ (1999) Consequences of evolving with bacterial symbionts: insights from the squid-vibrio associations. Annu Rev Ecol Syst 30:235-256

Miller TE, ter Horst CP (2012) Indirect effects in communities and ecosystems: ecology. Oxford bibliographies in ecology. https ://doi.org/10.1093/obo/9780199830060-0020

Moran NA, Sloan DB (2015) The hologenome concept: helpful or hollow? PLoS Biol 13(12):e1002311. https://doi.org/10.1371/ journal.pbio.1002311

Nyholm SV, McFall-Ngai M (2004) The winnowing: establishing the squid-vibrio symbiosis. Nat Rev Microbiol 2(8):632-642. https://doi.org/10.1038/nrmicro957

Nyholm SV, Bart Deplancke H, Gaskins R, Apicella MA, McFallNgai MJ (2002) Roles of Vibrio fischeri and nonsymbiotic bacteria in the dynamics of mucus secretion during symbiont colonization of the Euprymna scolopes light organ. Appl Environ Microbiol 68(10):5113-5122

Odling-Smee FJ, Laland KN, Feldman MW (2003) Niche construction: the neglected process in evolution. Monogr Popul Biol. https://press.princeton.edu/titles/7691.html
Queller DC, Strassmann JE (2016) Problems of multi-species organisms: endosymbionts to holobionts. Biol Philos 31(6):855-873. https://doi.org/10.1007/s10539-016-9547-x

Ram Y, Liberman U, Feldman MW (2018) Evolution of vertical and oblique transmission under fluctuating selection. Proc Natl Acad Sci USA. https://doi.org/10.1073/pnas.1719171115

Rand DM (2001) The units of selection on mitochondrial DNA. Ann Rev Ecol Syst 32:415-448

Rice WR (2013) Nothing in genetics makes sense except in light of genomic conflict. Annu Rev Ecol Evol Syst 44(1):217-237. https://doi.org/10.1146/annurev-ecolsys-110411-160242

Rosenberg E, Zilber-Rosenberg I (2018) The hologenome concept of evolution after 10 years. Microbiome 6(1):78. https://doi. org/10.1186/s40168-018-0457-9

Roughgarden J, Gilbert SF, Rosenberg E, Zilber-Rosenberg I, Lloyd EA (2017) Holobionts as units of selection and a model of their population dynamics and evolution. Biol Theory 13(1):44-65. https://doi.org/10.1007/s13752-017-0287-1

Sachs JL, Skophammer RG, Regus JU (2011) Evolutionary transitions in bacterial symbiosis. Proc Natl Acad Sci USA 108(Supplement 2):10800-10807. https://doi.org/10.1073/pnas.11003 04108

Sachs JL, Skophammer RG, Bansal N, Stajich JE (2014) Evolutionary origins and diversification of proteobacterial mutualists. Proc R Soc Lond B 281(1775):20132146. https://doi. org/10.1098/rspb.2013.2146

Sawabe T, Ogura Y, Matsumura Y, Gao F, Rohul Amin AKM et al (2013) Updating the Vibrio clades defined by multilocus sequence phylogeny: proposal of eight new clades, and the description of Vibrio tritonius Sp. Nov. Front Microbiol. https ://doi.org/10.3389/fmicb.2013.00414

Sober E, Wilson DS (1998) Unto others: the evolution and psychology of unselfish behavior. Harvard University Press, Cambridge

Stanton ML (2003) Interacting guilds: moving beyond the pairwise perspective on mutualisms. Am Nat 162(S4):S10-S23. https ://doi.org/10.1086/378646

Stencel A, Wloch-Salamon DM (2018) Some theoretical insights into the hologenome theory of evolution and the role of microbes in speciation. Theory Biosci 137(2):197-206. https://doi. org/10.1007/s12064-018-0268-3

Strauss SY (1991) Indirect effects in community ecology: their definition, study and importance. Trends Ecol Evol 6(7):206-210. https://doi.org/10.1016/0169-5347(91)90023-Q

Szathmáry E (2015) Toward major evolutionary transitions theory 2.0. Proc Natl Acad Sci USA. https://doi.org/10.1073/ pnas. 1421398112

Szathmáry E, Smith JM (1995) The major evolutionary transitions. Nature 374(6519):227-232. https://doi.org/10.1038/374227a0

Theis KR, Dheilly NM, Klassen JL, Brucker RM, Baines JF et al. (2016) Getting the hologenome concept right: an eco-evolutionary framework for hosts and their microbiomes. MSystems. https://doi.org/10.1128/mSystems.00028-16

Thompson JN (1994) The coevolutionary process. University of Chicago Press, Chicago

Van Dyken JD, Wade MJ (2012) Detecting the molecular signature of social conflict: theory and a test with bacterial quorum sensing genes. Am Nat 179:436-450

Vermeij GJ (1994) The evolutionary interaction among species: selection, escalation, and coevolution. Annu Rev Ecol Syst 25(1):219 236. https://doi.org/10.1146/annurev.es.25.110194.001251

Wade MJ (1980) Kin selection: its components. Science 210(4470):665-667. https://doi.org/10.1126/scien ce. 210.4470 .665 
Wade MJ (2007) The co-evolutionary genetics of ecological communities. Nat Rev Genet 8(3):185-195. https://doi.org/10.1038/ nrg2031

Wade MJ (2014) Paradox of mother's curse and the maternally provisioned offspring microbiome. Cold Spring Harbor Perspect Biol. https://doi.org/10.1101/cshperspect.a017541

Wade MJ (2016) Adaptation in metapopulations: how interaction changes evolution. University of Chicago Press, Chicago

Wade MJ, Breden FJ (1980) The evolution of cheating and selfish behavior. Behav Ecol Sociobiol 7:167-172

Wade MJ, Breden FJ (1981) The effect of inbreeding on the evolution of altruistic behavior by kin selection. Evolution 35:844-858

Wade MJ, Goodnight CJ (2006) Cyto-nuclear epistasis: two-locus random genetic drift in hermaphroditic and dioecious species. Evolution 60:643-659

Weiblen GD, Treiber EL (2015) Evolutionary origins and diversification of mutualism. In: Bronstein JL (ed) Mutualism. Oxford University Press, Oxford, pp 37-56, http://www.oxfor dscholarship.com/view/10.1093/acprof:oso/9780199675 654.001.0001/acprof-9780199675654-chapter-3

Williams GC (1966) Adaptation and natural selection. Princeton University Press, Princeton

Williams GC (1990) Review of the structure and confirmation of evolutionary theory, by Elisabeth A. Lloyd. Q Rev Biol 65(4):504

Wolf JB, Brodie Iii ED, Cheverud JM, Moore AJ, Wade MJ (1998) Evolutionary consequences of indirect genetic effects. Trends Ecol Evol 13(2):64-69

Wollenberg MS, Ruby EG (2009) Phylogeny and fitness of Vibrio fischeri from the light organs of Euprymna scolopes in two
Oahu, Hawaii populations. ISME J 6(2):352-362. https://doi. org/10.1038/ismej.2011.92

Wootton JT (1994) The nature and consequences of indirect effects in ecological communities. Annu Rev Ecol Syst 25(1):443-466. https://doi.org/10.1146/annurev.es.25.110194.002303

Yamamura N (1993) Vertical transmission and evolution of mutualism from parasitism. Theor Popul Biol 44(1):95-109

Yamamura N (1996) Evolution of mutualistic symbiosis: a differential equation model. Res Popul Ecol 38(2):211-218

Yildiz FH, Visick KL (2009) Vibrio biofilms: so much the same yet so different. Trends Microbiol 17(3):109-118

Young KH (1998) Yeast two-hybrid: so many interactions, (in) so little time. Biol Reprod 58(2):302-311

Zarubin M, Belkin S, Ionescu M, Genin A (2012) Bacterial bioluminescence as a lure for marine zooplankton and fish. Proc Natl Acad Sci USA 109(3):853-857. https://doi.org/10.1073/ pnas. 1116683109

Zilber-Rosenberg I, Rosenberg E (2008) Role of microorganisms in the evolution of animals and plants: the hologenome theory of evolution. FEMS Microbiol Rev 32(5):723-735. https://doi. org/10.1111/j.1574-6976.2008.00123.x

Publisher's Note Springer Nature remains neutral with regard to jurisdictional claims in published maps and institutional affiliations. 